\title{
Testing the Construct Validity of a Proposed Measurement Model of Mobile Applications in the Learning Process Using Confirmatory Factor Analysis
}

\author{
Altaher Alssaid M Alssaid1, Dr. Noor Azizi Bin Ismail², Dr. Noorhayti Binti Hashim ${ }^{3}$ \\ ${ }^{1,2,3}$ Faculty of Major Languages Studies, Universiti Science Islamic Malaysia (USIM). Bandar Baru Nilai, 71800 Nilai, Negeri \\ Sembilan, Malaysia
}

\begin{abstract}
The present study to test the validity of a proposed research model to measuring mobile phone applications in the learning process at the faculties physical education-Libya through several dimensions: characteristics, possibilities, importance and readiness. In order to achieve this, the researchers used a Confirmatory Factor Analysis (CFA) through the Amos program. The results of the analysis showed that the proposed research model was valid, and it can be relied upon to be used for measuring mobile phone applications in the learning process.
\end{abstract}

Keywords: characteristics, importance, possibilities, readiness

\section{Introduction}

Nowadays, the world is witnessing a rapidly growing development in various fields, particularly, in the area of technology. Technology in its multiple and various forms has become an essential requirement of this modern age where the technical progress or advancement is penetrating all fields including education that has been given its adequate share of this advancement. Increasing the social interaction through mobile phone applications has become a unique demand for learning styles since applications provide learners with the opportunities to interact and share content, flexibility as well as self-learning. Therefore, curriculum and syllabus designers are required to give more attention to mobile phone applications to support student learning: both individually and collaboratively or in groups (Baird \& Fisher, 2005).

Regarding this, some previous studies (Jonas-Dwyer et al, 2012) have pointed out at teachers' and students' use of mobile devices for educational purposes, which is one of the most important technologies that have spread among people in a very fast and amazing manner. Previous researchers have observed the spread of mobile applications among people in the society in general and in particular, among students both males and females. As stated by (Tang\& Helps, 2010), this can be attributed to the powerful and pervasive use of these technological devices as well as their importance as a means to learning in education.

In a study by (Motivalla,2007), the students found that mobile applications as a free and a good means for classroom interaction, a tool for discussing courses with peers as well as with teachers and a useful tool for learning. It also provided them with the opportunity to access from anywhere, and it is convenient to use, and effective in providing personal content. In general, the results of the same study revealed that the students were satisfied with mobile applications to learning.

From this point the researchers design model that can be relied upon to measure the extent of the use of mobile applications in the educational process.

\section{Research Objectives}

The current study aimed to test the validity of a proposed model for measuring use of mobile phone applications in the educational processat the faculties physical education-Libyan Universities.

\section{Method}

\subsection{Study Population and Sample}

the study population consists of faculty members or teaching staff at the faculties physical education-Libyan Universities, a number of $(\mathrm{N}=1573)$ lecturer. However, due to the large size of this faculties. The sample size was set determined by 1:5 according to the number of items of the questionnaire $(\mathrm{N}=88$ items) (sekaran,2003). Therefore, the sample size was (440), and based on this, 450 questionnaires were distributed to the participants, but only ( $\mathrm{N}=404)$ questionnaires were valid for the analysis, thus representing or accounting for (89\%) of the overall number of the questionnaires distributed to the participants.

\subsection{Research Instruments}

In this regard, it is relied upon the questionnaire as a tool to gather the necessary information for this study as one of the most suitable scientific research tools that achieve the survey study objectives and to obtain information and facts associated with a determined reality, for achieving the study, a questionnaire is made for the purposes of processing the studying test the validity of a proposed model for measuring 


\section{International Journal of Science and Research (IJSR) \\ ISSN (Online): 2319-7064}

Index Copernicus Value (2013): 6.14 | Impact Factor (2014): 5.611

use of mobile phone applications in the educational processat the faculties physical education-Libyan Universities.

\subsection{Confirmatory Factor Analysis}

The Structural Equation Modeling (AMOS) model-fitting program is used to test the validity constructs are to test the research hypotheses. The overall model fit is assessed by using four indices of the model goodness-of-fit: (1) the comparative fit index (CFI); (2) the minimum value of the discrepancy between the observed data and the hypothesized model divided by degrees of freedom (CMIN/DF) or normed chi-square (Marsh and Hocevar,1985). (3) The chi-square statistics (McDonald and Marsh, 1990); (4) Inaddition (RMSEA) of between (0.08) to (0.10) indicates a mediocre fit (Browne and Cudeck, 1993) and would not employ a model a (RMSEA) greater than $0.1(>0.1)$ (MacCallu um et al., 1996).

\subsection{Construct Validity}

The employment of factor loading composite reliability (CR) and average variance extracted (AVE) were proposed by (Hair, Black, Babin, Anderson and Tatham, 2006) to determine the convergent validity if it equals to or greater than $0.5(\geq 0.5)$ and the composite reliability equals to or greater than $0.7(\geq 0.7)$ (Hair et al, 2006). In addition (AVE) reading values should be greater than $0.5(\geq 0.5)$ (Fornel and Larker, 1981), and greater than (Shared Variance-SV).

\section{Results}

\subsection{The Modified Model}

From Figure (1) that shows the results of the (CFA) for the proposed model for measuring mobile phone applications in the educational processat the faculties physical educationLibyan Universities, it is evident that the model is free of the illogical correlation since it reaches or exceeds the integer (1). This also indicates that there is not any problems in the (CFA) used for testing the validity of this model that comprises four factors: The first factor including the Characteristics, the second factor including theImportance and the third factor containing thePossibilities, the fourth factor including the Readiness. As seen in Figure (1) and Table (1), the indicators of agreement between the model and the data exceeded the T-value, thus, implying that there is disagreement between The use of mobile applications in the educational process and the data of the sample since the value of the Chi-Square was (644.582) and the degree of freedom was (113), and the level of significance was $(\mathrm{P}=.000)$. In addition, we can see that the normative Chi-Square (ChiSquare/degrees of freedom) was (5.704) which did not exceed (5) and the value of Comparative Fit Index (CFI)was (.891) less than the T-value (.90). The results also show that the value of the index (RMSEA) error square was (.108) being higher than (.080). Due to this contradiction between the model and the data, it was necessary to modify the use of mobile applications in the educational process model in this study.

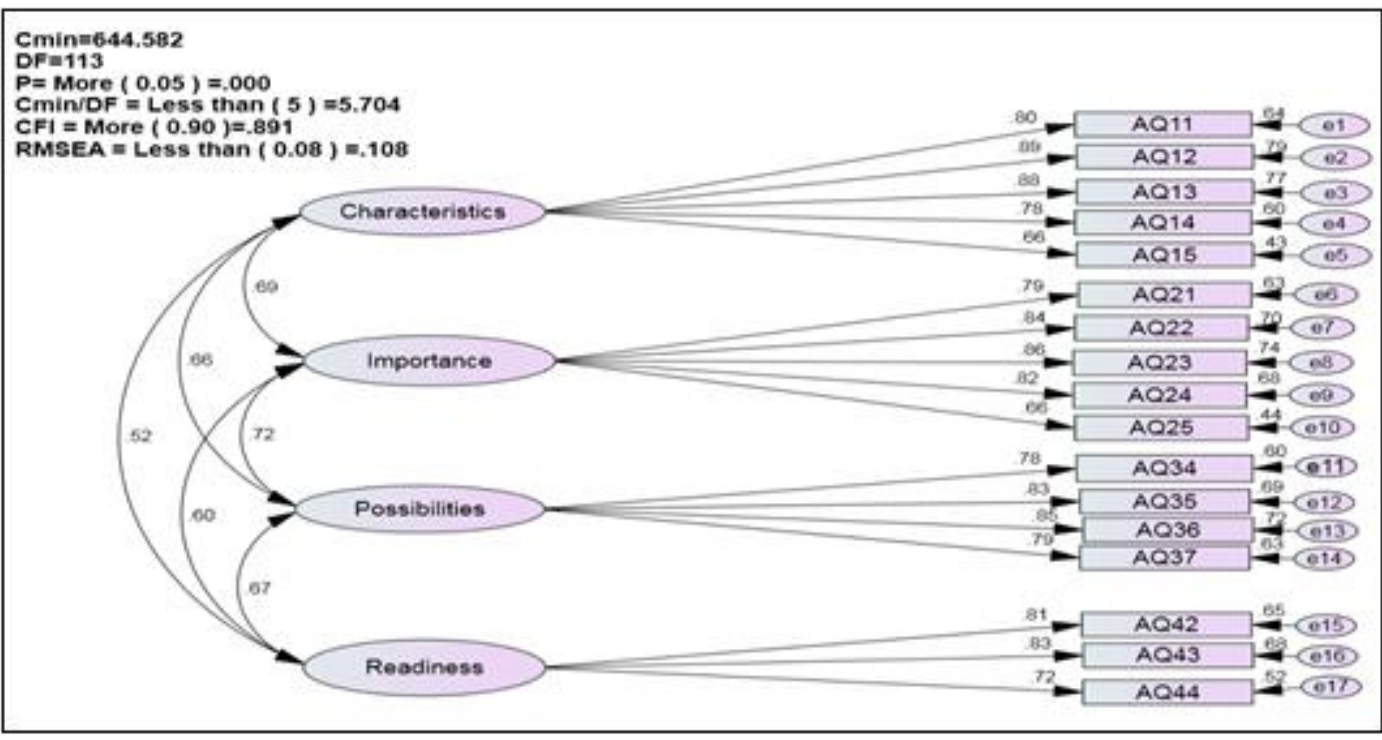

Figure 1: Model Mobile phone usage in the educational process before the amendment

In order to modify this model, we followed two steps:

Connecting some of the items as Figure (2). The second

step was deleting two items (AQ14CFA, AQ24CFA).

Table 1: Index Value of Mobile phone usage in the educational process model before and after modification

\begin{tabular}{|c|c|c|c|}
\hline indicators consistency & index value before modification & index value after modification & Function value on the quality of conformity \\
\hline Cmin & 644.582 & 279.665 & --- \\
\hline $\mathrm{df}$ & 113 & 80 & --- \\
\hline P & .000 & .000 & Non \\
\hline Cmin/Df & 5.704 & 3.496 & Less than (5) \\
\hline CFI & .891 & .950 & Less (0.90) \\
\hline Rmsea & .108 & .079 & $(0.08)$ \\
\hline
\end{tabular}




\section{International Journal of Science and Research (IJSR) \\ ISSN (Online): 2319-7064 \\ Index Copernicus Value (2013): 6.14 | Impact Factor (2014): 5.611}

4.2 Confirmatory Factor Analysis of the Mobile phone usage in the educational process model

The results of the goodness-of-fit of the final revised of the Mobile phone usage in the educational process model showed that normed chi- square (CMIN/DF) was (3.496) the (CFI) was (.950) and (RMSEA)was (.079). Figure (2) shows the adequacy of the final revised of the Mobile phone usage in the educational process model.

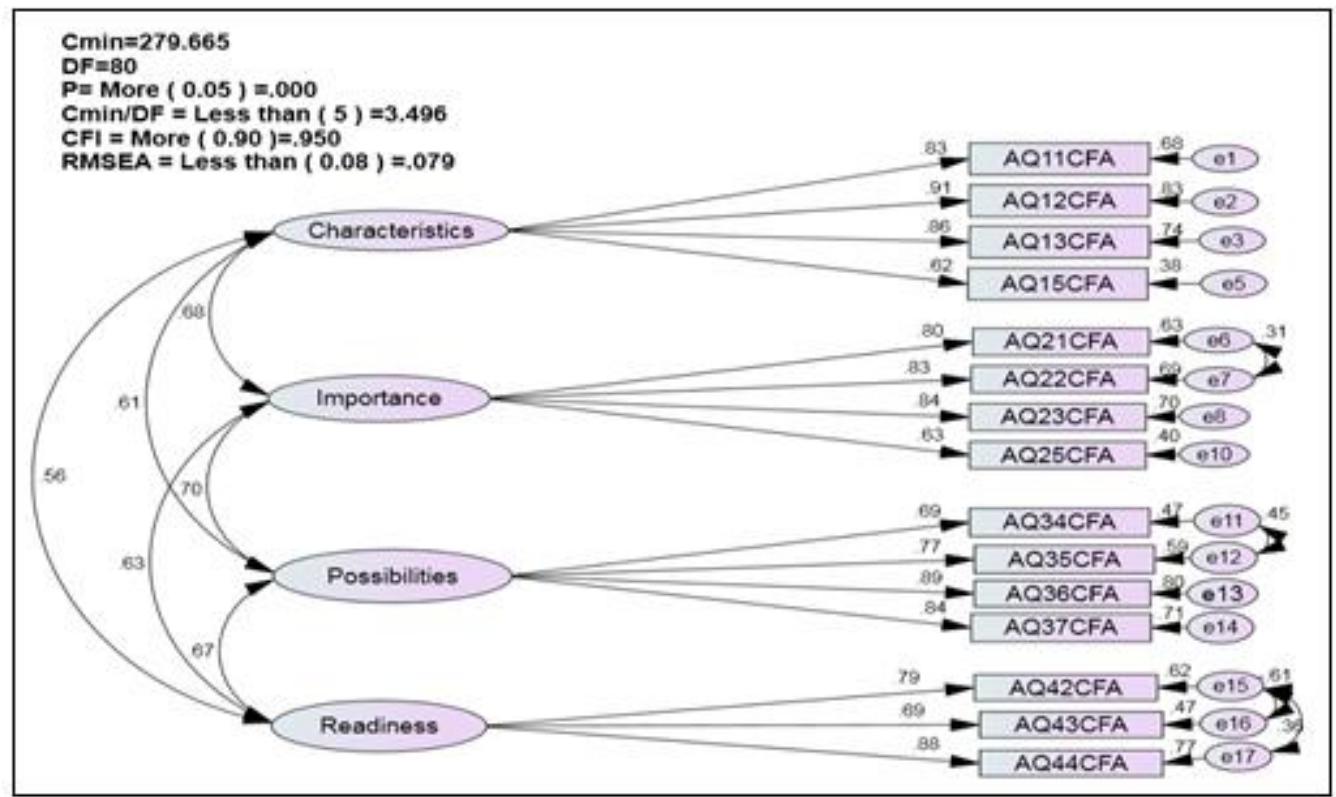

Figure 2: Mobile phone usage in the educational process model after amendment

Table 2: Shared Variance between the dimensions of

Mobile phone usage in the educational process model

\begin{tabular}{|c|c|c|c|c|}
\hline Variables & Characteristics & Importance & Possibilities & Readiness \\
\hline Characteristics & 1 & & & \\
\hline Importance & .37 & 1 & & \\
\hline Possibilities & .46 & .49 & 1 & \\
\hline Readiness & .31 & .44 & .39 & 1 \\
\hline
\end{tabular}

\subsection{Construct Validity and Reliability}

\subsubsection{Characteristics the Mobile phone}

Table 3: Construct Validity and Reliability of Mobile phone usage in the educational process model-Characteristics the Mobile phone

\begin{tabular}{|c|c|c|c|c|c|c|c|c|c|c|}
\hline $\begin{array}{l}\text { Item } \\
\text { code }\end{array}$ & variables & Items & Reliability & estimate & S. E. & C. R. & $\mathrm{P}$ & Loading & $\mathrm{R}$ & AVE \\
\hline AQ11 & \multirow{4}{*}{ Characteristics } & Mobile phones are easy tocarry. & .96 & .962 & .044 & 22.111 & .000 & .83 & .68 & .65 \\
\hline AQ12 & & Mobile phones are easy to use. & .96 & 1.000 & - & - & - & .91 & .83 & - \\
\hline AQ13 & & Mobile phones are safe. & .96 & .921 & .039 & 23.746 & .000 & .86 & .74 & - \\
\hline AQ15 & & $\begin{array}{l}\text { You can re-sore the saved information } \\
\text { in mobiles. }\end{array}$ & .96 & .694 & .050 & 13.901 & .000 & .62 & .38 & - \\
\hline
\end{tabular}

\subsubsection{Importance the Mobile phone}

In the paper, the factor lodging for the parameters ranged from (.69 to .89), with all parameters were above (0.5) $(\geq 0.5)$. The reliability all items was (.96), were greater than $(0.7)(\geq 0.7)$. Furthermore, the (AVE) readings was (.64) where the value was greater than $(0.5)(\geq 0.5)$, in addition to
In this study, the factor lodging for the parameters ranged from (.62 to.91), with all parameters were above $(0.5)(\geq 0.5)$. The reliability all items was (.96), were greater than $(0.7)$ $(\geq 0.7)$. Furthermore, the (AVE) readings was (.65) where the value was greater than $(0.5)(\geq 0.5)$,in addition to was greater than (SV)as depicted in table (2) ,Generally, the Characteristics of the Mobile phone usage in the educational processmodel was fit and fulfilled the construct as depicted in table (3). was greater than (SV)as depicted in table (2), Generally, the Importance of the Mobile phone usage in the educational processmodel was fit and fulfilled the construct as depicted in table (4). 


\section{International Journal of Science and Research (IJSR) \\ ISSN (Online): 2319-7064 \\ Index Copernicus Value (2013): 6.14 | Impact Factor (2014): 5.611}

Table 4: Construct Validity and Reliability of Mobile phone usage in the educational process model-Importance the Mobile phone

\begin{tabular}{|c|c|c|c|c|c|c|c|c|c|c|}
\hline $\begin{array}{l}\text { Item } \\
\text { code }\end{array}$ & variables & Items & Reliability & estimate & S. E. & C. R. & $\mathrm{P}$ & Loading & $\mathrm{R}$ & AVE \\
\hline AQ34 & \multirow{4}{*}{ Importance } & $\begin{array}{l}\text { I can send and receive many visual } \\
\text { recordings. }\end{array}$ & .96 & .786 & .050 & 15.617 & .000 & .80 & .63 & .60 \\
\hline AQ35 & & $\begin{array}{l}\text { I can re-use the Internet from my } \\
\text { mobile phone. }\end{array}$ & .96 & .866 & .047 & 18.342 & .000 & .83 & .69 & - \\
\hline AQ36 & & \begin{tabular}{|c|}
$\begin{array}{c}\text { Mobile phones provide the means for } \\
\text { clarifications. }\end{array}$ \\
\end{tabular} & .96 & 1.000 & - & - & - & .84 & .70 & - \\
\hline AQ37 & & \begin{tabular}{|c|} 
Using mobile phone technology in \\
teaching enhances the strength of the \\
lecture.
\end{tabular} & .96 & .976 & .046 & 21.261 & .000 & .63 & .40 & - \\
\hline
\end{tabular}

4.3.3.Possibilities the Mobile phone: In the study, the factor lodging for the parameters ranged from (.63 to .84), with all parameters were above $(0.5)(\geq 0.5)$. The reliability all items was (.96), were greater than $(0.7)(\geq 0.7)$. Furthermore, the (AVE) readings was (.60) where the value was greater than
(0.5) $(\geq 0.5)$, in addition to was greater than (SV)as depicted in table (2) , Generally, the Possibilities of the Mobile phone usage in the educational processmodel was fit and fulfilled the construct as depicted in table (5).

Table 5: Construct Validity and Reliability of Mobile phone usage in the educational process model-Possibilities the Mobile

\begin{tabular}{|c|c|c|c|c|c|c|c|c|c|c|}
\hline Item code & variables & Items & \begin{tabular}{|l} 
Reliability \\
\end{tabular} & estimate & S. E. & C. R. & $P$ & Loading & $\mathrm{R}$ & AVE \\
\hline AQ21 & \multirow{4}{*}{ Possibilities } & $\begin{array}{l}\text { Learning by using a mobile phone can } \\
\text { be accessed or available anywhere and } \\
\text { anytime. }\end{array}$ & .96 & .917 & .054 & 16.891 & .000 & .69 & .47 & .64 \\
\hline AQ22 & & $\begin{array}{l}\text { Learning through mobile phones offers } \\
\text { an immediate support for the learner. }\end{array}$ & .96 & .955 & .053 & 17.877 & .000 & .77 & .59 & - \\
\hline AQ23 & & $\begin{array}{l}\text { Learning through mobile phones helps } \\
\text { in communication between the teacher } \\
\text { and the learner. }\end{array}$ & .96 & 1.000 & - & - & - & .89 & .80 & - \\
\hline AQ25 & & $\begin{array}{l}\text { Learning through mobile phones } \\
\text { increases the educational values of } \\
\text { learning. }\end{array}$ & .96 & .717 & .054 & 13.243 & .000 & .84 & .71 & - \\
\hline
\end{tabular}

\subsubsection{Readiness the Mobile phone}

In the present study, the factor lodging for the parameters ranged from (.69 to .88), with all parameters were above $(0.5)(\geq 0.5)$. The reliability all items was (.96), were greater than $(0.7)(\geq 0.7)$. Furthermore, the (AVE) readings was (.62) where the value was greater than $(0.5)(\geq 0.5)$, in addition to was greater than (SV)as depicted in table (2) Generally, the Readiness of the Mobile phone usage in the educational processmodel was fit and fulfilled the construct as depicted in table (6).

Table 6: Construct Validity and Reliability of Mobile phone usage in the educational process model-Readiness the Mobile phone

\begin{tabular}{|c|c|c|c|c|c|c|c|c|c|c|}
\hline $\begin{array}{l}\text { Item } \\
\text { code }\end{array}$ & variables & Items & Reliability & estimate & S. E. & C. R. & $\mathrm{P}$ & Loading & $\mathrm{R}$ & AVE \\
\hline AQ42 & \multirow{3}{*}{ Readiness } & $\begin{array}{l}\text { Learning through mobile phone technology assists in } \\
\text { developing my experiences. }\end{array}$ & .96 & .882 & .076 & 11.620 & .000 & .79 & .62 & .62 \\
\hline AQ43 & & Using mobile phone technologies is encouraging. & .96 & .789 & .067 & 11.690 & .000 & .69 & .47 & - \\
\hline AQ44 & & $\begin{array}{l}\text { Learning through mobile phone technologies in } \\
\text { facilitates interaction. }\end{array}$ & .96 & 1.000 & - & - & - & .88 & .77 & - \\
\hline
\end{tabular}

\section{Conclusion}

The current study aimed to test the validity of a proposed research model to measuring mobile phone applications in the learning process at the faculties physical educationLibyan Universities. The model comprised mobile phone applications as the latent factor through several underlying variables: characteristics, possibilities, importance and readiness. In achieving this research goal, the researcher used a Confirmatory Factor Analysis (CFA) through the Amos program. This was also intended to test the validity of the model in measuring or determining mobile phone applications in the learning process. After analysis the data as shown in Figure (2) and Table (1), it was found that there is a contradiction between the model and the data, which confirms the need for modifying the model by deleting the item (AQ14CFA, AQ24CFA), as well as connecting some items as illustrated in Figure (2). Thus, after amending and modifying the model as in Figure (2) and Tables $(3,4,5,6)$, there is a goodness of fit between the model and the data based on the congruence indices including the values of the (average variance extracted-AVE) for all variables which were higher than (.50) and also higher than the (shared covariance-SV). Therefore, the proposed model was characterized by convergent validity, and the same time, discriminant. This means that the model is valid to be used 
for measuring mobile phone applications in the learning process.

\section{References}

[1] Baird D. E., \& Fisher M. (2005). Neomillennial UserExperience Design Strategies: Utilizing Social Networking Media to Support Always-on Learning Styles. Journal of Educational Technology.

[2] Browne, M. W., \& Cudeck, R. (1993). Alternative ways of assessing model fit. "Sage. Focus Editions, 154, 136.

[3] Fornell, C., \& Larcker, D. F. (1981). Evaluating structural equation models with unobservable variables andmeasurement error. Journal of Marketing Research, 18(1), 39-50.

[4] Hair, J. F., Anderson, R. E., Tatham, R. L. \& Black, W. C. (2006). Multivariate Data Analysis (5th ed.), New Jersey, Prentice-Hall.

[5] Jonas-Dwyer, D., Clark, C., Celenza, T., \& Siddiqui, Z. (2012). Evaluating Apps for Learning.

[6] Mac Callum, R. C., Browne, M. W., \& Sugawara, H. M. (1996). Power Analysis and Determination of Sample.

[7] Marsh, H. W., \& Hocevar, D. (1985). Application of confirmatory factor analysis to the study of selfconcept: First-and higher order factor models and their invariance across groups. "Psychological bulletin", 97(3), 562-582. http://dx.doi.org/10.1037/00332909.97.3.562.

[8] McDonald, R. P., \& Marsh, H. W. (1990). Choosing a multivariate model: Noncentrality and goodness of fit. "Psychological Bulletin", 107(2), 247-255.

[9] Motivalla, L. (2007). Mobile Learning: A Framework and Evaluation. Computers \& Education, 49, 81Participation \& Lifelong Learning, 14, 25-41.Systems, 34 (1), 5-32.

[10] Sekaran, U.2003. Research Methods for Business: A Skill Building Approach (4 $4^{\text {th }}$ Ed). New York: Wiley. SILVERMAN, D.2000.Doing Qualitative Research.

[11] Tang, C., \& Helps, R. (2010). Mobile Application Development: Essential New Directions for IT. Paper presented at Seventh International Conference on Information Technology, Las Vegas, USA, 471-475. 